\title{
Additive manufacturing of a novel alpha titanium alloy from commercially pure
}

\section{titanium with minor addition of $\mathrm{Mo}_{2} \mathrm{C}$}

X.P. Li ${ }^{\text {a,b,c*}}{ }^{*}$ G. Ji ${ }^{d}$, K. Eder ${ }^{\text {e }}$, L.M. Yang ${ }^{\text {e }}$, A. Addad ${ }^{d}$, J. Vleugels ${ }^{f}$, J. Van Humbeeck ${ }^{f}$, J.M. Cairney ${ }^{\mathrm{e}}$, J.P. Kruth ${ }^{\mathrm{a}, \mathrm{c}}$

${ }^{a}$ KU Leuven (University of Leuven), Department of Mechanical Engineering, Leuven 3001, Belgium

b School of Mechanical and Manufacturing Engineering, The University of New South Wales, Sydney 2052, Australia

${ }^{\text {c }}$ Member of Flanders Make vzw, Leuven 3001, Belgium

d Unité Matériaux et Transformations, CNRS UMR 8207, Université Lille 1, Villeneuve d’Ascq 59655, France

e AMME and Australian Centre for Microscopy and Microanalysis, The University of Sydney, Sydney 2006, Australia

${ }^{\mathrm{f}}$ KU Leuven (University of Leuven), Department of Materials Engineering, Leuven 3001, Belgium

Corresponding author email: xiaopeng.li@unsw.edu.au

Abstract: In this study, a fully dense and crack-free alpha titanium alloy was fabricated using selective laser melting (SLM) of commercially pure titanium (CP Ti) blended with 1 vol.\% micrometre-sized $\mathrm{Mo}_{2} \mathrm{C}$ powder. The microstructure and mechanical properties of the fabricated Ti alloy were systematically investigated. It was found that the fabricated Ti alloy consisted of both alpha $(\alpha)$ and beta $(\beta)$ phases and exhibited a nest-like inhomogeneous 
microstructure with graded local phase formation, composition and crystallographic texture. This novel microstructure was formed through melting and rapid solidification of CP Ti and $\mathrm{Mo}_{2} \mathrm{C}$ during SLM, assisted by the high laser absorptivity and resultant high temperature rise of the $\mathrm{Mo}_{2} \mathrm{C}$ powder. The fabricated $\mathrm{Ti}$ alloy exhibited higher tensile strength $(\sim 1250 \pm 50$ MPa) and improved ductility (elongation $\sim 17 \pm 1 \%$ ) when compared to CP Ti fabricated using the same SLM process. The underlying reasons were mainly attributed to (i) the nest-like inhomogeneous microstructure consisting of fine grained $\alpha$-Ti and $\beta$-Ti, (ii) the overall solid solution strengthening of the Ti matrix by interstitial C, and (iii) the high dislocation density in the Ti matrix arising from the mismatch between $\alpha$-Ti and $\beta$-Ti phases. This study not only provides a fundamental knowledge about the modification of $\mathrm{CP} \mathrm{Ti}$ with minor addition of secondary particles through SLM but also provides insight into the fabrication of inhomogeneous Ti alloys with graded microstructure and local composition through SLM for enhanced mechanical properties.

Key words: Additive manufacturing; Selective laser melting; Titanium alloys; Commercially pure titanium; Graded microstructure.

\section{Introduction}

Commercially pure titanium (CP-Ti) is an important engineering material with broad applications in various industries, especially in the chemical and petrochemical sectors, due to their excellent fabricability and superior environmental resistance (e.g., corrosion resistance) in service [1]. However, the insufficient strength of CP-Ti severely impedes their implementation for applications where mechanical properties are equally important to corrosion resistance. Unfortunately, the available options for strengthening CP-Ti are relatively few and practically limited to solid solution strengthening (i.e., by interstitials and 
substitutional elements), grain boundary strengthening, and dispersing secondary reinforcing particles into CP-Ti. As an example, great efforts have been devoted in the past decades to modifying CP-Ti either through traditional substitutional alloying with trace amount of elements including Pd or $\mathrm{Ru}(\leq 2 \%)$ or designing and fabricating titanium matrix composites (TMCs) by introducing secondary particles or fibres into CP-Ti [1-5]. However, the conventional alloying approach is costly and very limited regarding the enhancement of mechanical properties of CP-Ti, while the conventional processing of TMCs is time-, energyand material-consuming due to its high melting point $\left(\sim 1668^{\circ} \mathrm{C}\right)$ and high affinity to oxygen at elevated temperatures. Moreover, post-processing or machining of the fabricated TMCs is also difficult due to their high strength and high hardness [1].

As an emerging powder-based additive manufacturing technique, selective laser melting (SLM) produces metal components in a layer-wise fabrication manner from a computer-aided design (CAD) model [6, 7]. Apart from its widely-known advantages over conventional processing techniques such as high freedom of custom design, production of complex geometries and no need for post-machining processes, etc. [6, 7], it also features another two unique characteristics. The first characteristic is the cyclic heating and cooling process with very high heating and cooling rate due to the short interaction time and volume between the laser and materials [8]. This high cooling rate in SLM allows the fabrication of very fine microstructure with small grain size in many alloys as well as supersaturated nonequilibrium microstructure with higher concentration of solute elements. The second characteristic is the fabrication of new alloys of varying compositions by SLM of a mixture of two or more powders, arising from the powder metallurgy origin of the SLM manufacturing process. This flexibility of processing powder mixtures by SLM enables the design and fabrication of metal matrix composites (MMCs) reinforced by various secondary particles. As such, by producing very fine and supersaturated microstructure or MMCs, SLM 
has opened up new opportunities to strengthen existing metals and alloys by solid solution strengthening, grain boundary strengthening, and introducing secondary particles to form composites, which are the most important three strengthening methods for CP-Ti. Therefore, SLM has been considered another promising alternative to the modification of CP-Ti and the design and fabrication of various strengthened Ti alloys or TMCs without post-machining. Some pioneering studies have been reported in recent years [9-13]. Fisher et al. reported the fabrication of a binary Ti-26Nb alloy by SLM from elemental Ti and Nb mixed powders. A homogeneous $\beta$-Ti alloy with non-columnar but elongated grains was achieved [14]. Gu et al. reported on the fabrication of TMCs by SLM of a mixture of CP Ti and micrometre-sized SiC particles. The microstructure showed a unique network of distributed $\mathrm{TiC}$ and a submicrometre dendritic morphology, which resulted in high microhardness $\left(980 \mathrm{HV}_{0.2}\right)$ and a low friction coefficient [15]. Apart from this, similar attempts were also made to fabricate other TMCs via SLM including Ti-TiC nanocomposites, in-situ $\mathrm{Ti}^{-\mathrm{TiB}_{2}}$ composites and $\mathrm{TiB}$ reinforced near $\alpha$-Ti metal composites from $\mathrm{CP} \mathrm{Ti}$ and micrometre-sized $\mathrm{CrB}_{2}$ [16-18]. Although these studies result in the fabrication of fully dense and crack-free $\mathrm{Ti}$ alloys or TMCs with improved mechanical properties by manipulating the SLM processing parameters, they all introduced a relatively large quantity of secondary particles ( $\geq 5 \mathrm{vol} . \%$ ) to either form TMCs or form a substantial amount of $\beta$-Ti phase in the CP-Ti for strengthening purposes. For example, the secondary particles in previous studies (e.g., $\mathrm{TiC}$ and $\mathrm{TiB}$ ) either remain intact after SLM or react with CP-Ti to induce the formation of a new compound in the matrix during SLM. As such, the role of solid solution strengthening in these SLMed Ti alloys or TMCs cannot be decoupled from the influence of large amount of $\beta$-Ti phase or residual/newly-formed secondary particles. Hence, another important strengthening mechanism in $\mathrm{CP}-\mathrm{Ti}$, namely the solid solution strengthening mechanism, has not been systematically investigated and fully understood in SLMed CP-Ti, in particular the influence 
of interstitials and substitutional elements. Moreover, most of these fabricated Ti alloys or TMCs have a relatively homogeneous microstructure where the understanding in local tailorable microstructure and composition by adding secondary particles were not provided and are still unclear. Hence, it becomes crucial and necessary to investigate the important role of solid solution strengthening mechanism in CP-Ti through SLM of CP-Ti with a minor addition of secondary particles. Following this, the influence of the minor additions on the local microstructure and composition in the SLMed CP-Ti and hence the resultant mechanical properties can also be investigated and understood.

In this study, since $\mathrm{Mo}_{2} \mathrm{C}$ contains both $\mathrm{Mo}$ and $\mathrm{C}$ and a small amount of $\mathrm{Mo}_{2} \mathrm{C}$ is supposed to be fully melted and dissolved into Ti according to equilibrium phase diagram, $\mathrm{Mo}_{2} \mathrm{C}$ was chosen as the source of interstitials and substitutional elements to CP-Ti. By optimising the SLM processing parameters, a fully dense and crack-free $\alpha$-Ti alloy was obtained by SLM of CP-Ti with 1 vol.\% $\mathrm{Mo}_{2} \mathrm{C}$ particles. The microstructure and mechanical properties of the SLMed Ti alloy were systematically investigated. In contrast to previous studies, most of the $\mathrm{Mo}_{2} \mathrm{C}$ particles were fully melted and entered into the Ti matrix as Mo and $\mathrm{C}$ to form solid solutions and no TiC was formed. Importantly, the fabricated Ti alloy exhibited a nest-like inhomogeneous microstructure and showed a higher tensile strength (around 1250 $\pm 50 \mathrm{MPa}$ ) and improved ductility (elongation around $17 \pm 1 \%$ ) in comparison with the SLMed CP Ti. The underlying reason for this is discussed in detail. This study provides a promising alternative for strengthening $\mathrm{CP}$-Ti by solid solution strengthening mechanism and fabricating inhomogeneous $\mathrm{Ti}$ alloys with graded microstructure and composition through SLM for better mechanical properties.

\section{Experimental procedures}




\subsection{Powder materials and laser absorptivity}

Commercially pure titanium powder (CP Ti, Grade 1, LPW, UK) with powder particle size from 15 to $45 \mu \mathrm{m}$ and molybdenum carbide powder $\left(\mathrm{Mo}_{2} \mathrm{C}\right.$, Changsha Langfeng, China) with an average powder particle size $\sim 3.5 \mu \mathrm{m}$ were used in this study. $\mathrm{Mo}_{2} \mathrm{C}$ powder was added to the $\mathrm{CP} \mathrm{Ti}$ powder to make up a volume fraction of $1 \%$ and the powder was mixed in a multidirectional mixer for $4 \mathrm{~h}$ to ensure a homogeneous distribution. The laser absorptivity of the $\mathrm{CP} \mathrm{Ti}$ powder, $\mathrm{Mo}_{2} \mathrm{C}$ powder and the mixed powder were measured using diffuse reflectance spectroscopy (DRS). DRS was carried out in the 250 to $2250 \mathrm{~nm}$ wavelength range using an UV-Visible-NIR Lambda 950 Perkin Elmer spectrometer equipped with a $150 \mathrm{~mm}$ diameter integrating sphere coated with Spectralon with $1 \mathrm{~nm}$ spectral resolution. A Spectralon reference was used to measure the $100 \%$ reflectance and internal attenuators were used to determine zero reflectance in order to remove background and noise. The powders were placed in a quartz cuvette, sealed, and mounted on a Teflon sample holder for the DRS measurement.

\subsection{Selective laser melting (SLM)}

The mixed powder was used to produce Ti alloy specimens $(10 \times 10 \times 10 \mathrm{~mm})$ and standard tensile bars on an in-house built selective laser melting machine which is equipped with a fibre laser, with a wavelength of $1.06 \mu \mathrm{m}$ and maximum power of $300 \mathrm{~W}$ on the part bed. An inert, high purity ( $\geq 99.99 \%$ ) argon gas atmosphere flow was used during the whole process to minimise oxidation. Optimal laser power and scanning speed were used to fabricate fully dense and crack-free specimens based on previous investigations [19]. The powder layer thickness was fixed at $30 \mu \mathrm{m}$, the scan spacing at $60 \mu \mathrm{m}$, without pre-heating. For comparison, CP Ti specimens $(10 \times 10 \times 10 \mathrm{~mm})$ were also produced using SLM with the 
same optimised parameters. A total of 10 specimens were fabricated for both Ti alloy and CP Ti.

\subsection{Microstructure characterisation}

The microstructure of the powder materials and SLMed Ti alloy was characterised using a FEI-Nova NanoSEM 450 scanning electron microscope (SEM, acceleration voltage $10 \mathrm{kV}$, working distance $5 \mathrm{~mm}$ ) and a FEI Tecnai G2 transmission electron microscope (TEM, operated at $200 \mathrm{kV}$ ). A state-of-the-art FEI Titan Themis 300 TEM, equipped with a probe aberration corrector and a highly efficient (4 quadrant) energy dispersive X-ray (EDX) system and operated at $200 \mathrm{kV}$, was further used for atomic and nanoscale characterization in the scanning TEM mode. The TEM $3 \mathrm{~mm}$ disc samples from the SLMed Ti alloy were mechanically polished and finally thinned by a Precision Ion Polishing System (Gatan PIPS $^{\mathrm{TM}}$ ) where low-angle and low-current polishing conditions were used in conjunction with a liquid nitrogen cold stage. Texture and grain size of SLMed Ti alloy were characterised by electron backscattered diffraction (EBSD) using a TSL orientation imaging microscope system mounted on a FEI-Nova NanoSEM 450 SEM (step size of $0.1 \mu \mathrm{m}$ ), and also by nanobeam diffraction using a Nanomages Astar system on a Tecnai G2 TEM (beam size of around $2 \mathrm{~nm}$ and step size of $10 \mathrm{~nm}$ ). TEM Astar data was post treated using ATOM software [20].

Atom probe tomography (APT) was carried out on the SLMed Ti alloy. For specimen preparation, the samples were dissected into $0.5 \mathrm{~mm} \times 0.5 \mathrm{~mm}$ square rods, which were then sharpened via electropolishing to create the needle shaped specimens required for APT analysis. Electropolishing was conducted at $38 \mathrm{~V}$, with an electrolyte of $5 \%$ perchloric acid in $30 \%$ n-butoxyelethnol and $65 \%$ methanol cooled down to $-31^{\circ} \mathrm{C}$. The obtained tips where then sharpened in a Zeiss Auriga FIB-SEM to ensure that the needles had a tip diameter of less than $80 \mathrm{~nm}$ and that the surface was free of protrusions and dimples. The atom probe 
experiments were carried out on a Cameca LEAP 4000X Si in laser pulsing mode at a specimen temperature of $\sim 50 \mathrm{~K}$, a pulse rate of $250 \mathrm{kHz}$, a pulse energy of $80 \mathrm{pJ}$ and a target evaporation between $0.5-1 \%$. IVAS 3.6.8 software was used to reconstruct and visualise the APT data.

The phase formation in the powder and SLMed Ti alloy was characterised using Xray diffraction (XRD, Siemens D500 powder diffractometer, $\mathrm{Cu} \mathrm{K \alpha}$ target, operated at $40 \mathrm{kV}$ and $40 \mathrm{~mA}$ with a step size of $0.02^{\circ}$ and scanning speed $2^{\circ} / \mathrm{min}$, all XRD scans were done on the plane parallel to the SLM building direction). Since the oxygen and nitrogen pick-up during SLM can possibly influence the mechanical properties of the SLMed alloys, an inert gas fusion technique using a commercial analyser of the type Leco ONH836 was applied for quantitative analysis of the oxygen and nitrogen contents of the SLMed Ti alloy and the starting powder.

\subsection{Mechanical properties}

Standard tensile tests were carried out on SLMed and machined Ti alloy specimens (gauge length $\sim 4 \times 2 \times 16 \mathrm{~mm}$, prepared by electrical discharge machining, EDM), using an Instron 5982 machine at a constant strain rate of $1 \mathrm{~mm} / \mathrm{min}$. Strain was measured with a 12.5 mm gauge length extensometer. Samples were aligned perpendicular to the build direction and a total of 5 samples were tested. In addition, in order to in situ observe the tensile behaviour (e.g., slip bands) of the samples, SLMed CP Ti and Ti alloy micro-tensile specimens were prepared by EDM from the fabricated $10 \times 10 \times 10 \mathrm{~mm}$ cubes, followed by careful polishing. In-situ micro-tensile tests were carried out on the SLMed and machined specimens (gauge length $\sim 2 \times 0.5 \times 6 \mathrm{~mm}$ ) using Deben MICROTEST $200 \mathrm{~N}$ modules at a constant extension rate of $0.05 \mathrm{~mm} / \mathrm{min}$ in a FEI-Nova NanoSEM 450 SEM. Samples were aligned perpendicular to the build direction and a total of 10 samples were tested. 


\section{Results}

\subsection{Mixed powder and laser absorptivity}

The morphology of the $\mathrm{CP} \mathrm{Ti}, \mathrm{Mo}_{2} \mathrm{C}$ and the mixed powder with 1 vol.\% $\mathrm{Mo}_{2} \mathrm{C}$ is shown in Figure 1. The CP $\mathrm{Ti}$ powder has a spherical shape, which is the typical gasatomised powder morphology while the $\mathrm{Mo}_{2} \mathrm{C}$ powder has an irregular shape. After mechanical mixing for $4 \mathrm{~h}$, the micrometre-sized $\mathrm{Mo}_{2} \mathrm{C}$ powder distributes relatively homogeneously. Although the majority of the $\mathrm{Mo}_{2} \mathrm{C}$ particles are attached to the surface of the CP Ti powder, due to the fact that only 1 vol. $\% \mathrm{Mo}_{2} \mathrm{C}$ was added, no deterioration in the flowability of the CP Ti powder was expected. The laser reflectivity and K-M absorption factor were used to assess the laser absorptivity of the $\mathrm{CP} \mathrm{Ti}, \mathrm{Mo}_{2} \mathrm{C}$ and the mixed powders (for comparison, $\mathrm{CP} \mathrm{Ti}$ powder with 5 and 10 vol.\% of $\mathrm{Mo}_{2} \mathrm{C}$ were also prepared and measured). As shown in Figure 2, the laser reflectivity of $\mathrm{Mo}_{2} \mathrm{C}$ powder and $\mathrm{CP} \mathrm{Ti}$ powder at $1.06 \mu \mathrm{m}$ laser wavelength was measured to be $\sim 22 \%$ and $\sim 30 \%$, respectively. With increasing the amount of $\mathrm{Mo}_{2} \mathrm{C}$ powder, the laser reflectivity of the mixed powder decreased. Specifically for the addition of 1 vol.\% $\mathrm{Mo}_{2} \mathrm{C}$ powder in this study, the laser reflectivity of the mixed powder was reduced to $\sim 27 \%$. This indicates that even a small addition of $\mathrm{Mo}_{2} \mathrm{C}(1$ vol.\%) can result in an improved laser absorptivity.

\subsection{Microstructure of the SLMed Ti alloy}

The phase formation in the $\mathrm{CP} \mathrm{Ti}$ and $\mathrm{Mo}_{2} \mathrm{C}$ powder as well as the SLMed Ti alloy specimens is shown in Figure 3. Both $\mathrm{CP}$ Ti powder and the $\mathrm{Mo}_{2} \mathrm{C}$ powder have a hexagonal close packed (hcp) crystal structure. Only $\alpha$-Ti was detected in the CP Ti powder while no $\beta$ Ti (body centred cubic, bcc Ti) was observed. In the SLMed Ti alloy, along with the peaks from $\alpha$-Ti a tiny peak corresponding to $\beta$-Ti appeared, signifying the formation of a small amount of $\beta$-Ti in the SLMed Ti alloy. In addition, the relative peak intensity in the SLMed 
Ti alloy and the CP Ti remains identical. This implies that no strong crystallographic texture was formed after SLM.

The microstructure of the SLMed Ti alloy in the cross-section parallel to the building direction is shown in the back-scattered SEM (BSE) image in Figure 4a. No cracks have been observed. An inhomogeneous microstructure consisting of three distinct areas with different contrast, i.e. dark area, light grey area and bright grey area can be readily seen. The SEM energy dispersive X-ray spectroscopy (EDX) results corresponding to these areas are shown in Figure 4b. The dark area mainly contains Ti without any Mo being detected, while the light grey and bright grey areas contain a lower amount and higher amount of Mo apart from Ti, respectively. This indicates that most of the $\mathrm{Mo}_{2} \mathrm{C}$ particles were melted and dissolved into $\mathrm{Ti}$ during SLM. However, it is noteworthy that very few $\mathrm{Mo}_{2} \mathrm{C}$ powder particles were also observed embedded in the Ti alloy matrix, as shown in the inset image in Figure 4a. From the spherical morphology of the residual $\mathrm{Mo}_{2} \mathrm{C}$ powder particles which was different from its starting irregular morphology, it can be speculated that these $\mathrm{Mo}_{2} \mathrm{C}$ particles also underwent a melting process during SLM.

The EBSD results of the SLMed Ti alloy in the cross-section parallel to the building direction are shown in Figure 5. From the inverse pole figure (IPF) image as shown in Figure 5a, two different regions can be observed. Both regions contain fine grains but one with elongated grains and the other with equiaxed grains. The two regions also showed a nest-like distribution where the regions with elongated grains were surrounded by the regions with equiaxed grains. The corresponding phase map shown in Figure 5b showed that the regions with elongated grains were $\alpha$-Ti while the regions with equiaxed grains were $\beta$-Ti and no martensitic $\alpha^{\prime}$ phase has been observed. According to the random colour in the IPF image, no strong crystallographic texture was formed in the SLMed Ti alloy, consistent with the XRD 
result in Figure 3. However, as shown in the pole figures in Figure 5c, a strong local crystallographic texture developed in the $\alpha$-Ti region while a relatively weak crystallographic texture was formed in the $\beta$-Ti region.

To further reveal the inhomogeneous microstructure in the SLMed Ti alloy, a detailed investigation was conducted using TEM. It can be seen from Figure 6a that the elongated lath-like grains were surrounded by very fine equiaxed grains. According to the electron diffraction patterns shown in Figure 6b, the elongated grains are $\alpha$-Ti and the equiaxed grains are $\beta$-Ti, consistent with the SEM EBSD results shown in Figure 5. TEM nano-beam diffraction was also conducted on the SLMed $\mathrm{Ti}$ alloy which provided more detailed information about the local grain structure and phase formation, as shown in Figure 7. Both $\alpha$-Ti and $\beta$-Ti exhibited very fine grain structures and distributed inhomogeneously in the Ti matrix. Interestingly, in contrast to previously reported SLMed metals with very low dislocation density [21], a large dislocation density exhibited in the SLMed Ti alloy in both $\alpha$-Ti and $\beta$-Ti grains as shown in Figure 7d, implying that the heat dissipated from subsequent deposited and scanned layers cannot fully anneal out the dislocations formed during SLM. Since Mo is known as a $\beta$-Ti phase stabiliser, the distribution of the Mo in the $\beta$-Ti grain clusters was investigated using STEM EDX, as shown in Figure 8. It can be seen that the $\beta$-Ti grain boundaries were enriched with Mo while Mo was also detected inside the $\beta$-Ti grains, indicating that the distribution of Mo was inhomogeneous even at the nanoscale. To reveal the distribution of light elements, especially C, atom probe tomography (APT) was used. Figure 9a shows a reconstruction of the SLMed Ti alloy, containing only $5 \%$ of the Ti ions and $100 \%$ of the Mo and $\mathrm{C}$ ions. The remaining ions (e.g., $\mathrm{O}$ and $\mathrm{N}$ ) detected during the analysis are very low and are not shown here, in order to improve the visibility of the other ions. An inhomogeneous distribution of Mo and $\mathrm{C}$ within the dataset was found. To better highlight the distribution of $\mathrm{C}$ and Mo within the dataset, iso-concentration surfaces of $\mathrm{C}$ 
(blue), and iso-density surfaces of Mo (red) were created in Figure 9b, with a C concentration of 0.75 at\% and an atomic density of $0.44 \mathrm{Mo} / \mathrm{nm}^{3}$. It can be seen that C and Mo are not located in the same areas. This is the case for all analysed datasets both in the matrix and along grain boundaries. A proxigram of all Mo iso-surfaces contained within the dataset is shown in Figure 9c, which further emphasises that the location of $\mathrm{C}$ and Mo is not correlated. Proxigrams are a 3D concentration distribution profile, which show the composition in the vicinity of an interface, and are generated by calculating a composition profile of all elements present within an iso-surface, with respect to their distance from the local normal of the interface [22]. This indicates that upon the melting and solidification of $\mathrm{CP} \mathrm{Ti}$ and $\mathrm{Mo}_{2} \mathrm{C}, \mathrm{C}$ as an interstitial element can diffuse into the Ti matrix and then freezes inside the grains, probably as a result of the rapid cooling process during SLM. Analyses of the oxygen and nitrogen contents of the SLMed Ti alloys and the starting powders are listed in Table 1 which demonstrates that the oxygen and nitrogen pick-up during SLM is negligible.

\subsection{Mechanical properties of the SLMed Ti alloy}

Both standard tensile tests and in-situ micro-tensile tests were carried out to investigate the tensile behaviour of the SLMed Ti alloy and SLMed CP Ti as a comparison. The stress-strain curves of the standard and micro-tensile tests are shown in Figure 10. The SLMed CP Ti showed a tensile strength and elongation $\sim 760 \pm 30 \mathrm{MPa}$ and $15 \pm 1 \%$, respectively. In contrast, the SLMed Ti alloy exhibited a much higher tensile strength and slightly higher elongation of $\sim 1250 \pm 50 \mathrm{MPa}$ and $17 \pm 1 \%$, respectively (it should be pointed out that the relatively lower deformation strain in the micro-tensile specimens is mainly due to the fact that no physical extensometer was used for micro-tensile tests in this study. Therefore, the observed strain in the stress-strain curves (Figure 10b) is a combined result of the deformation from both the tensile testing stage (Deben MICROTEST 200N modules) and the micro-tensile specimens). The fracture surfaces of the SLMed Ti alloy and SLMed CP Ti 
from the micro-tensile tests are given in Figures 11a and 11b. It is clear that the SLMed CP Ti failed with a $45^{\circ}$ angle relative to the loading direction while the SLMed Ti alloy failed perpendicular to the loading direction. Both have apparent necking, i.e., a typical ductile fracture behaviour. Some large voids can be readily seen on the fracture surface of the SLMed CP Ti. In addition, a higher number of slip bands can be seen near the fracture surface of the SLMed Ti alloy while very limited slip bands can be observed in the SLMed

CP Ti. This again demonstrates the better ductility in SLMed Ti alloy than the SLMed CP Ti. Another close look at the fracture surfaces of the SLMed Ti alloy as shown in the BSE images in Figure 11c reveals that a high amount of micro-cracks formed in the dark area, which contained none or a low content of Mo. These micro-cracks were parallel to each other and perpendicular to the direction of the elongated grains which also had a small angle (mostly $\leq 10^{\circ}$ ) with the loading direction. This indicates that the failure in SLMed Ti alloy probably started in the elongated lath-like $\alpha$-Ti grains which aligned along or close to the loading direction.

\section{Discussion}

\subsection{Microstructure of the SLMed Ti alloy}

Recently, manipulation of microstructures in SLMed metal components for improved mechanical properties has been realised through controlling the processing parameters in SLM including laser power, scan speed, hatch spacing and preheating temperature. As a result of the directional global heat flux and local high cooling rates, a characteristic microstructure consisting of ultrafine grains with or without strong crystallographic texture can be achieved in steel, Al-, Ti-, Ni- alloys, and high entropy alloys [23-29]. Although some inhomogeneous microstructures with different phases and grain sizes can be obtained, site- 
specific tailoring of the local microstructure, composition, phase formation and crystallographic texture is still challenging by simply manipulating the SLM parameters. The main reason for this is that there is little to no control over the local thermal profiles. Introduction of secondary particles provides an effective way of altering local thermal profiles as the secondary particles normally have a different laser absorptivity compared to the matrix. This will result in a different temperature rise in the secondary particles and the matrix, which can be potentially utilised to tailor the local microstructure during SLM.

In this study, $\mathrm{Mo}_{2} \mathrm{C}$ shows higher laser absorptivity than $\mathrm{CP} \mathrm{Ti}$, as shown in Figure 2. This will induce a much higher temperature rise in $\mathrm{Mo}_{2} \mathrm{C}$ particles, similar to previous studies on SLM of ceramic particles reinforced Al-Si alloys [21, 30-32]. Based on these studies, this higher temperature rise in the $\mathrm{Mo}_{2} \mathrm{C}$ is also expected to promote the melting and dissolving of the $\mathrm{Mo}_{2} \mathrm{C}$ particles into $\mathrm{Ti}$, as evidenced by the three distinct areas in the SLMed Ti alloy matrix (Figure 4a) and the spherical morphology of the residual $\mathrm{Mo}_{2} \mathrm{C}$ particles. However, due to the low content of $\mathrm{Mo}_{2} \mathrm{C}$ (1 vol.\%) which is lower than the concentration required for the formation of $\mathrm{TiC}$ [33], no TiC was formed during SLM while Mo and C dissolved in the Ti matrix. It is noteworthy that apart from fully melting the $\mathrm{Mo}_{2} \mathrm{C}$ particles might also be partially dissolved into the melt pool during SLM. However, further investigations will be needed to uncover this effect. Mo is a well-known $\beta$-Ti stabiliser and this is why $\beta$-Ti formed in the SLMed Ti alloy [1]. In addition, since SLM has a very high local cooling rate and the interaction time between laser and materials is very short (a few milliseconds), Mo does not have enough time to diffuse for a long distance within the melt pool which normally has a width and depth around 100 and $150 \mu \mathrm{m}$, respectively [34]. This is consistent with our previous study on SLM of metallic glasses where heavy elements tend to diffuse over a shorter distance compared to light elements [35]. It is worth pointing out that the convection flow in the melt pool can push the $\mathrm{Mo}_{2} \mathrm{C}$ as well as Mo to the edge and bottom of the melt 
pool during SLM. Therefore, the distribution of dissolved Mo in the SLMed Ti alloy is inhomogeneous, with most of the dissolved Mo distributed along the edge and bottom of the melt pool. This results in a local graded microstructure with graded composition where the concentration of Mo gradually changes from the centre to the edge of the melt pool. Since no or less Mo was distributed around the core region of the melt pool, mainly $\alpha$-Ti was formed. This is why a nest-like microstructure consisting of $\alpha$-Ti and $\beta$-Ti was observed in the SLMed Ti alloy and regions with different Mo content (Figure 5).

No martensitic $\alpha^{\prime}$ phase has been observed in the SLMed Ti alloy. The formation of $\alpha^{\prime}$ phase is well known in SLM of CP Ti or Ti alloys due to the high cooling rates [36, 37]. Our previous studies have shown the critical role of cooling rate in martensitic transformation in SLM of CP Ti [19]. Considering that identical SLM processing parameters were used in this study compared to our previous studies and only 1 vol.\% of $\mathrm{Mo}_{2} \mathrm{C}$ was added into the $\mathrm{CP} \mathrm{Ti}$ matrix, a similar global heat flux can be assumed. Therefore, the underlying cause for the absence of $\alpha^{\prime}$ phase in SLMed Ti alloy would be related to the local heat profiles which have been modified by the higher temperature rise in $\mathrm{Mo}_{2} \mathrm{C}$ as mentioned above. This is why only lath-like elongated $\alpha$-Ti was observed inside the melt pool, surrounded by $\beta$-Ti formed by the melting and dissolving of $\mathrm{Mo}_{2} \mathrm{C}$ into $\mathrm{CP}$ Ti. According to the TEM results, Mo was distributed inhomogeneously in the $\beta$-Ti regions, enriched at the $\beta$-Ti grain boundaries. These Mo-enriched grain boundaries can impede the grain growth during solidification during SLM. This is why the size of the $\beta$-Ti grains is much smaller than for the $\alpha$-Ti grains.

In general, SLMed metal components show a strong textured microstructure due to the directional global heat flux and large thermal gradient that exist during the SLM process. The crystallographic texture can be altered or modified by varying the scanning patterns [28, 29]. The underlying mechanism lies in the manipulation of the global heat flux behaviour 
during SLM. In addition, there are a few other factors which can influence the crystallographic texture formation including stresses generated by volume change as well as some characteristic grain boundaries which favour nucleation of certain orientation, phase formation, etc. [38]. In this study, although the global heat flux during SLM of Ti alloy cannot be severely altered by addition of this small amount of $\mathrm{Mo}_{2} \mathrm{C}$, the local thermal profile around the $\mathrm{Mo}_{2} \mathrm{C}$ can be influenced due to its higher laser absorptivity and higher temperature rise during SLM, especially in the region where the $\beta$-Ti formed. As a result, a relatively weak crystallographic texture formed inside the $\beta$-Ti region while a strong crystallographic texture formed in the $\alpha$-Ti region which is less influenced by $\mathrm{Mo}_{2} \mathrm{C}$ (Figure 5), which is in contrast to the strong crystallographic texture in the SLMed CP $\mathrm{Ti}$ [22]. Therefore, the formation of texture during SLM of Ti alloy in this study is actually a combined mechanism consisting of both global heat flux and local thermal profile. In contrast to previously reported SLM of aluminium nanocomposites where no high dislocation densities were observed due to the dislocations being annealed out by the heat dissipated during SLM [21], high dislocation densities were detected in this study in the SLMed Ti alloy. The reason for this is attributed to the diffusion of Mo into CP Ti matrix to form $\beta$-Ti phases where a strong mismatch exists between $\alpha$-Ti and $\beta$-Ti phases.

\subsection{Mechanical properties of the SLMed Ti alloy in comparison with SLMed CP Ti}

It is known that there are several key mechanisms for enhancing the mechanical properties (e.g., strength and ductility) of a metallic material. These mechanisms include grain boundary strengthening, Orowan and loading-bearing strengthening via secondary particles, increased dislocation density strengthening, bimodal grain structure and nonequilibrium grain boundaries, etc. In this study, since only very few $\mathrm{Mo}_{2} \mathrm{C}$ particles were left and no TiC was formed in the SLMed Ti alloy, the observed strengthening of SLMed Ti alloy compared to SLMed CP Ti is probably due to solid solution hardening, strengthening by high 
dislocation density and grain boundary hardening rather than precipitation hardening. In details, the tensile properties enhancement of SLMed Ti alloys in this study is mainly attributed to: (1) the solid solution strengthening due to interstitial $\mathrm{C}$ which is distributed inside the $\alpha$-Ti phase; (2) the high dislocation density arising from the mismatch between $\alpha$ Ti and $\beta$-Ti phases; and (3) the graded and inhomogeneous microstructure consisting of nestlike fine $\alpha$-Ti and $\beta$-Ti with Mo enriched grain boundaries. As for solid solution hardening, it has been shown that Mo mainly distributed in the $\beta$-Ti phase while $\mathrm{C}$ was found mainly in the $\alpha$-Ti phase (Figures 8 and 9). Considering that Mo has a small effect on the lattice parameter of $\beta$-Ti and only 1 vol.\% $\mathrm{Mo}_{2} \mathrm{C}$ was added into $\mathrm{CP} \mathrm{Ti}$ in this study, the solid solution hardening effect from Mo is trivial. In contrast, the interstitial $\mathrm{C}$ is reported to have a significant strengthening effect in the $\alpha$-Ti phase even at very low concentration, similar to other interstitial elements such as $\mathrm{N}$ and $\mathrm{O}[1,39]$. Therefore, interstitial C plays a critical role in solid solution strengthening of the SLMed Ti alloy. As abovementioned, a high dislocation density was observed in the SLMed Ti alloy mainly arising from the mismatch between $\alpha$-Ti and $\beta$-Ti phases. This high dislocation density means that there is only a short distance between dislocations which can block the motion of each one during deformation, further contributing to the strengthening of the SLMed Ti alloy. In addition, the SLMed Ti alloy has a graded and inhomogeneous microstructure consisting of nest-like fine $\alpha$-Ti and $\beta$ Ti. The fine grained $\alpha$-Ti and $\beta$-Ti can also contribute to the enhanced strength in the SLMed Ti alloy, especially in the $\beta$-Ti where the grain boundaries are enriched with Mo which can impede the movement of dislocations. As a result, it can be seen that the enhancement in strength in the SLMed Ti alloy compared to SLMed CP Ti is mainly caused by the solid solution strengthening from interstitial $\mathrm{C}$ in $\alpha$-Ti, high dislocation density and the fine grained $\alpha$-Ti and $\beta$-Ti with Mo enriched grain boundaries. A similar result was also reported 
recently on SLM of stainless steel 316L with significantly enhanced mechanical properties due to high dislocation densities, novel microstructures, etc.[40].

It is known that $\mathrm{CP} \mathrm{Ti}$ can deform through both dislocation activated slip and deformation twinning and the fracture mechanism of CP $\mathrm{Ti}$ can be void nucleation and coalescence and/or cleavage fracture [1]. The plastic deformation and fracture mechanisms of CP Ti both depend on various factors including composition, grain size, and crystallographic texture and loading conditions $[1,41]$. In SLMed CP Ti, since the grain size is much smaller than the conventionally fabricated $\mathrm{CP} \mathrm{Ti}$, the operation of deformation twinning is restricted and the deformation in SLMed CP Ti is mainly activated through slip modes [1]. This reduces the plasticity of SLMed CP Ti and is why only a small number of slip bands can be seen in the deformed SLMed CP Ti. The large void at the fracture surface shows that a void mechanism is in operation and voids are mainly nucleated at $\alpha / \alpha$ grain boundaries. As for the $45^{\circ}$ angle between the fracture surface and the loading direction, the main reason for this is attributed to the well-known fact that the maximum shear stress exists along the plane with a $45^{\circ}$ angle to the loading direction. Although void nucleation and coalescence mechanism dictates the fracture of SLMed CP Ti, it is worth pointing out that due to the $h c p$ crystal structure of $\alpha$-Ti the crystallographic texture can also increase the propensity for cleavage fracture along the basal plan in $\alpha-\mathrm{Ti}$, especially in the SLMed CP $\mathrm{Ti}$ where strong crystallographic texture can exist locally [1, 42]. This can also influence the angle between the fracture surface and loading axis. Further investigations will be needed in the future to uncover the exact fracture mechanism. In the SLMed Ti alloy, $\alpha$-Ti has a lower strength than $\beta$-Ti, and therefore the cracks are expected to initiate in the $\alpha$-Ti regions when an external load applies. This is why cracks are mainly formed in the $\alpha$-Ti region. Although the propensity for cleavage fracture in $\alpha$-Ti decreases with decreasing grain size, the existence of interstitial $\mathrm{C}$ will increase the propensity for cleavage fracture in $\alpha$-Ti $[1,42]$. This cleavage 
fracture differs from the void nucleation mechanism induced fracture and depends on the stress along the basal plane of $\alpha-\mathrm{Ti}$, which can be influenced by the crystallographic texture of the $\alpha$-Ti $[1,42]$. This can be the reason why multiple parallel cracks in the $\alpha$-Ti were aligned perpendicular to the elongated $\alpha$-Ti grain (Figure 11). Upon further loading, these cracks in the $\alpha$-Ti region will propagate towards the $\beta$-Ti grains where $\alpha / \beta$ interfaces will act as a barrier to stop its further propagation and release the strain energy by initiating slip bands around the interface. As a result, a high density of slip bands can be observed in the deformed SLMed Ti alloy. Due to this slip transmission across the $\alpha / \beta$ interfaces and the relatively weak crystallographic texture in $\beta$-Ti the crack propagation direction will be perpendicular to the loading direction and this is why the fracture surface is perpendicular to the loading direction. As a result of this, the strength and ductility of the SLMed Ti alloys were both enhanced compared to the SLMed CP Ti.

\section{Conclusions}

In this study, a fully dense and crack-free $\alpha$-Ti alloy was obtained by SLM of CP Ti with 1 vol.\% micrometre-sized $\mathrm{Mo}_{2} \mathrm{C}$. The microstructure and mechanical properties of the SLMed Ti alloy were characterised and investigated in comparison with the SLMed CP Ti. The following conclusions can be drawn from this study:

(1) The minor addition of $\mathrm{Mo}_{2} \mathrm{C}$ can increase the laser absorptivity of the mixed $\mathrm{CP}$ $\mathrm{Ti}$ and $\mathrm{Mo}_{2} \mathrm{C}$ powders. Most of the $\mathrm{Mo}_{2} \mathrm{C}$ particles were fully melted and entered into the $\mathrm{Ti}$ matrix as Mo and $\mathrm{C}$ to form solid solutions, facilitated by the high temperature rise in $\mathrm{Mo}_{2} \mathrm{C}$. This results in the formation of three distinct areas with different concentrations of Mo in the SLMed Ti alloy. No TiC was detected, which was probably due to the fact that only a small amount of $\mathrm{Mo}_{2} \mathrm{C}$ was added to $\mathrm{CP}$ Ti. 
(2) The SLMed Ti alloy showed a nest-like inhomogeneous microstructure with graded local microstructure and local composition. Equiaxed $\beta$-Ti which was stabilised by Mo formed together with elongated $\alpha$-Ti in the SLMed Ti alloy. Mo was found enriched along the $\beta$-Ti grain boundaries while $\mathrm{C}$ was found as an interstitial in the Ti matrix and distributed inside the grains with some high concentrated areas. In addition, $\alpha$-Ti showed a strong crystallographic texture while $\beta$-Ti showed a relatively weak crystallographic texture. The formation of this microstructure was mainly attributed to the convection flow in the melt pool and the modified local thermal profiles during the SLM process.

(3) The fabricated Ti alloy exhibited a higher tensile strength ( 1250 $\pm 50 \mathrm{MPa})$ and slightly improved ductility ( $17 \pm 1 \%$ elongation) when compared to CP Ti fabricated using SLM. The underlying reason was attributed to the fine nest-like $\alpha / \beta$ microstructure, the solid solution strengthening by interstitial C, and the high dislocation density in the matrix.

\section{Acknowledgements}

This work was supported by the Flemish Agency for Innovation by Science and Technology (IWT) in the framework of Strategic Basic Research (SBO) project "MultiMet". The TEM facility in Lille, France, is supported by the Conseil Regional du Nord-Pas de Calais and the European Regional Development Fund (ERDF). The authors would also like to thank Dr. Wouter Baekelant from the Department of Chemistry, KU Leuven for powder laser absorptivity measurement, Prof. Changjiang Song from Shanghai University for chemical analysis, and Florant Exertier from the Australia Centre for Microscopy and Microanalysis for carrying out some of the electropolishing of the APT samples. 


\section{References}

[1] G. Lütjering, J.C. Williams, Titanium, Springer2007.

[2] T. Kuzumaki, O. Ujiie, H. Ichinose, K. Ito, Mechanical characteristics and preparation of carbon nanotube fiber-reinforced Ti composite, Advanced Engineering Materials 2(7) (2000) 416-418.

[3] C. Poletti, M. Balog, T. Schubert, V. Liedtke, C. Edtmaier, Production of titanium matrix composites reinforced with SiC particles, Composites Science and Technology 68(9) (2008) 2171-2177.

[4] K. Kondoh, T. Threrujirapapong, H. Imai, J. Umeda, B. Fugetsu, Characteristics of powder metallurgy pure titanium matrix composite reinforced with multi-wall carbon nanotubes, Composites Science and Technology 69(7) (2009) 1077-1081.

[5] S.C. Tjong, Y.-W. Mai, Processing-structure-property aspects of particulate-and whiskerreinforced titanium matrix composites, Composites Science and Technology 68(3) (2008) 583-601.

[6] I. Gibson, D.W. Rosen, B. Stucker, Additive manufacturing technologies, Springer2010.

[7] D. Gu, W. Meiners, K. Wissenbach, R. Poprawe, Laser additive manufacturing of metallic components: materials, processes and mechanisms, International materials reviews 57(3) (2012) 133-164.

[8] T. Vilaro, V. Kottman-Rexerodt, M. Thomas, C. Colin, P. Bertrand, L. Thivillon, S. Abed, V. Ji, P. Aubry, P. Peyre, Direct fabrication of a Ti-47Al-2Cr-2Nb alloy by selective laser melting and direct metal deposition processes, Advanced Materials Research, Trans Tech Publ, 2010, pp. 586-591.

[9] L.C. Zhang, H. Attar, Selective laser melting of titanium alloys and titanium matrix composites for biomedical applications: a review, Advanced Engineering Materials 18(4) (2016) 463-475. 
[10] D. Gu, Y.-C. Hagedorn, W. Meiners, K. Wissenbach, R. Poprawe, Nanocrystalline TiC reinforced Ti matrix bulk-form nanocomposites by Selective Laser Melting (SLM): Densification, growth mechanism and wear behavior, Composites Science and Technology 71(13) (2011) 1612-1620.

[11] H. Attar, L. Löber, A. Funk, M. Calin, L. Zhang, K. Prashanth, S. Scudino, Y. Zhang, J. Eckert, Mechanical behavior of porous commercially pure $\mathrm{Ti}$ and $\mathrm{Ti}-\mathrm{TiB}$ composite materials manufactured by selective laser melting, Materials Science and Engineering: A 625 (2015) 350-356.

[12] D. Gu, G. Meng, C. Li, W. Meiners, R. Poprawe, Selective laser melting of TiC/Ti bulk nanocomposites: Influence of nanoscale reinforcement, Scripta Materialia 67(2) (2012) 185188.

[13] B. Vrancken, L. Thijs, J.-P. Kruth, J. Van Humbeeck, Microstructure and mechanical properties of a novel $\beta$ titanium metallic composite by selective laser melting, Acta Materialia 68 (2014) 150-158.

[14] M. Fischer, D. Joguet, G. Robin, L. Peltier, P. Laheurte, In situ elaboration of a binary Ti-26Nb alloy by selective laser melting of elemental titanium and niobium mixed powders, Materials Science and Engineering: C 62 (2016) 852-859.

[15] D. Gu, Y.-C. Hagedorn, W. Meiners, K. Wissenbach, R. Poprawe, Selective Laser Melting of in-situ TiC/Ti5Si3 composites with novel reinforcement architecture and elevated performance, Surface and Coatings Technology 205(10) (2011) 3285-3292.

[16] H. Attar, M. Bönisch, M. Calin, L.-C. Zhang, S. Scudino, J. Eckert, Selective laser melting of in situ titanium-titanium boride composites: processing, microstructure and mechanical properties, Acta Materialia 76 (2014) 13-22.

[17] N. Kang, P. Coddet, Q. Liu, H. Liao, C. Coddet, In-situ TiB/near $\alpha$ Ti matrix composites manufactured by selective laser melting, Additive Manufacturing 11 (2016) 1-6. 
[18] B. He, K. Chang, W. Wu, C. Zhang, The formation mechanism of TiC reinforcement and improved tensile strength in additive manufactured Ti matrix nanocomposite, Vacuum 143 (2017) 23-27.

[19] X. Li, J. Van Humbeeck, J.-P. Kruth, Selective laser melting of weak-textured commercially pure titanium with high strength and ductility: A study from laser power perspective, Materials \& Design 116 (2017) 352-358.

[20] B. Beausir, J. Fundenberger, ATOM-Analysis Tools for Orientation Maps, Université de Lorraine - Metz, 2015.

[21] X. Li, G. Ji, Z. Chen, A. Addad, Y. Wu, H. Wang, J. Vleugels, J. Van Humbeeck, J.-P. Kruth, Selective laser melting of nano-TiB2 decorated AlSi10Mg alloy with high fracture strength and ductility, Acta Materialia 129 (2017) 183-193.

[22] B. Gault, M.P. Moody, J.M. Cairney, S.P. Ringer, Atom probe microscopy, Springer Science \& Business Media2012.

[23] J. Wu, X.Q. Wang, W. Wang, M.M. Attallah, M.H. Loretto, Microstructure and strength of selectively laser melted AlSi10Mg, Acta Materialia 117 (2016) 311-320.

[24] J. Suryawanshi, K.G. Prashanth, S. Scudino, J. Eckert, O. Prakash, U. Ramamurty, Simultaneous enhancements of strength and toughness in an Al-12Si alloy synthesized using selective laser melting, Acta Materialia 115 (2016) 285-294.

[25] N.J. Harrison, I. Todd, K. Mumtaz, Reduction of micro-cracking in nickel superalloys processed by selective laser melting: a fundamental alloy design approach, Acta Materialia 94 (2015) 59-68.

[26] Q. Jia, D. Gu, Selective laser melting additive manufacturing of Inconel 718 superalloy parts: Densification, microstructure and properties, Journal of Alloys and Compounds 585 (2014) 713-721. 
[27] W. Xu, M. Brandt, S. Sun, J. Elambasseril, Q. Liu, K. Latham, K. Xia, M. Qian, Additive manufacturing of strong and ductile Ti-6Al-4V by selective laser melting via in situ martensite decomposition, Acta Materialia 85 (2015) 74-84.

[28] L. Thijs, M.L. Montero Sistiaga, R. Wauthle, Q. Xie, J.-P. Kruth, J. Van Humbeeck, Strong morphological and crystallographic texture and resulting yield strength anisotropy in selective laser melted tantalum, Acta Materialia 61(12) (2013) 4657-4668.

[29] L. Thijs, K. Kempen, J.-P. Kruth, J. Van Humbeeck, Fine-structured aluminium products with controllable texture by selective laser melting of pre-alloyed AlSi10Mg powder, Acta Materialia 61(5) (2013) 1809-1819.

[30] X. Li, C. Kong, T. Becker, T. Sercombe, Investigation of interfacial reaction products and stress distribution in selective laser melted Al12Si/SiC composite using confocal Raman microscopy, Advanced Engineering Materials 18(8) (2016) 1337-1341.

[31] L.C. Astfalck, G.K. Kelly, X. Li, T.B. Sercombe, On the Breakdown of SiC during the Selective Laser Melting of Aluminum Matrix Composites, Advanced Engineering Materials 19(8) (2017).

[32] T. Sercombe, X. Li, Selective laser melting of aluminium and aluminium metal matrix composites, Materials Technology 31(2) (2016) 77-85.

[33] H. Okamoto, C-Ti (carbon-titanium), Journal of Phase Equilibria and Diffusion 19(1) (1998) 89-89.

[34] I. Yadroitsev, P. Krakhmalev, I. Yadroitsava, Selective laser melting of Ti6Al4V alloy for biomedical applications: Temperature monitoring and microstructural evolution, Journal of Alloys and Compounds 583 (2014) 404-409.

[35] X.P. Li, M.P. Roberts, S. O'Keeffe, T.B. Sercombe, Selective laser melting of Zr-based bulk metallic glasses: Processing, microstructure and mechanical properties, Materials \& Design 112(Supplement C) (2016) 217-226. 
[36] D. Gu, Y.-C. Hagedorn, W. Meiners, G. Meng, R.J.S. Batista, K. Wissenbach, R. Poprawe, Densification behavior, microstructure evolution, and wear performance of selective laser melting processed commercially pure titanium, Acta Materialia 60(9) (2012) 3849-3860.

[37] L. Thijs, F. Verhaeghe, T. Craeghs, J. Van Humbeeck, J.-P. Kruth, A study of the microstructural evolution during selective laser melting of Ti-6Al-4V, Acta Materialia 58(9) (2010) 3303-3312.

[38] S. Suwas, R.K. Ray, Crystallographic texture of materials, Springer2014.

[39] D. Simbi, J. Scully, The effect of residual interstitial elements and iron on mechanical properties of commercially pure titanium, Materials Letters 26(1-2) (1996) 35-39.

[40] Y.M. Wang, T. Voisin, J.T. McKeown, J. Ye, N.P. Calta, Z. Li, Z. Zeng, Y. Zhang, W. Chen, T.T. Roehling, Additively manufactured hierarchical stainless steels with high strength and ductility, Nature materials 17(1) (2018) 63.

[41] J. Williams, A. Sommer, P. Tung, The influence of oxygen concentration on the internal stress and dislocation arrangements in $\alpha$ titanium, Metallurgical and Materials Transactions B 3(11) (1972) 2979-2984.

[42] H. Nasiri-Abarbekoh, A. Ekrami, A. Ziaei-Moayyed, Impact of phase transformation on mechanical properties anisotropy of commercially pure titanium, Materials \& Design 37 (2012) 223-227.

Table 1 Chemical analysis for the SLMed Ti alloys and the starting powders

\begin{tabular}{ccc}
\hline Sample names & $\mathbf{O}_{\mathbf{2}} \mathbf{( p p m )}$ & $\mathbf{N}_{\mathbf{2}} \mathbf{( p p m )}$ \\
\hline Starting powders & 485 & 127 \\
SLMed Ti alloys & 517 & 135 \\
\hline
\end{tabular}




\section{Figure captions}

Fig. 1 SEM images of the morphology of (a) CP Ti powder, (b) $\mathrm{Mo}_{2} \mathrm{C}$ powder and (c) $\mathrm{CP} \mathrm{Ti}$ with 1 vol.\% $\mathrm{Mo}_{2} \mathrm{C}$ powder after mechanical mixing for $4 \mathrm{~h}$.

Fig. 2 The laser reflectivity of the $\mathrm{CP}$ Ti powder, the $\mathrm{Mo}_{2} \mathrm{C}$ powder and the mixed powders with different amounts (1, 5 and 10 vol.\%) of $\mathrm{Mo}_{2} \mathrm{C}$ powder. The dotted lines in black shows the laser wavelength used in the SLM machine in this study.

Fig. 3 XRD patterns of the $\mathrm{Mo}_{2} \mathrm{C}$ powder, the CP Ti powder, SLMed CP Ti and the SLMed Ti alloy. Red arrow points to the XRD peak which belongs to the $b c c \beta$-Ti and all other XRD peaks belong to hcp $\alpha$-Ti or $\mathrm{Mo}_{2} \mathrm{C}$.

Fig. 4 (a) Back-scattered electron (BSE) SEM images of the SLMed Ti alloy showing three distinct areas: dark area, light grey area and bright grey area. Inset shows the residual $\mathrm{Mo}_{2} \mathrm{C}$ powder in the SLMed Ti alloy. (b) SEM EDX point analysis spectra (from bottom to top) corresponding to the dark area, light grey area and bright grey area in (a), respectively.

Fig. 5 (a) EBSD orientation map of the SLMed Ti alloy measured in a section plane along the building direction (BD). The colour code representing the crystal orientation is included. (b) Corresponding phase map of the SLMed Ti alloy. (c) Pole figures showing the local crystallographic texture in the $\alpha$-Ti and $\beta$-Ti regions. Dotted squares in black in (a) and (b) show the $\alpha$-Ti region, acting as guidance for eyes for the nest-like microstructure.

Fig. 6 (a) TEM BF image of the SLMed Ti alloy. (b) Experimental and (c) Corresponding theoretical electron diffraction patterns of the $\alpha$-Ti and $\beta$-Ti phases. Black and red arrows point to the $h c p \alpha$-Ti and bcc $\beta$-Ti, respectively. 
Fig. 7 TEM Astar results of the SLMed Ti alloy: (a) Index map; (b) orientation map for $\alpha$-Ti phase; (c) orientation map for $\beta$-Ti phase; and (d) geometrically necessary dislocations map. Colour codes for $\alpha$-Ti and $\beta$-Ti are included, respectively.

Fig. 8 (a) STEM HAADF image of the SLMed Ti alloy and the corresponding STEM EDX maps showing the distribution of elements (b) Ti, (c) C and (d) Mo.

Fig. 9 (a) APT reconstruction containing Ti (5 \%), Mo (100\%) and C (100\%). (b) APT reconstruction showing the iso-concentration surface of $C$ ions in blue), and the iso-density surface of Mo ions in red. (c) Proxigram of all Mo iso-surfaces.

Fig. 10 Stress-strain curves for (a) the standard tensile tests of the SLMed Ti alloy and (b) the micro-tensile tests of the SLMed Ti alloy and SLMed CP Ti. Insets show the standard tensile specimens and micro-tensile specimens prepared using EDM from the SLMed Ti alloy (bottom inset in b is the micro-tensile specimen in SEM).

Fig. 11 The fracture surfaces of (a) the SLMed CP Ti, (b) the SLMed Ti alloy at low magnification and (c) the SLMed Ti alloy at high magnification. Black arrows in (b) and (c) point to the slip bands and micro-cracks, respectively. 

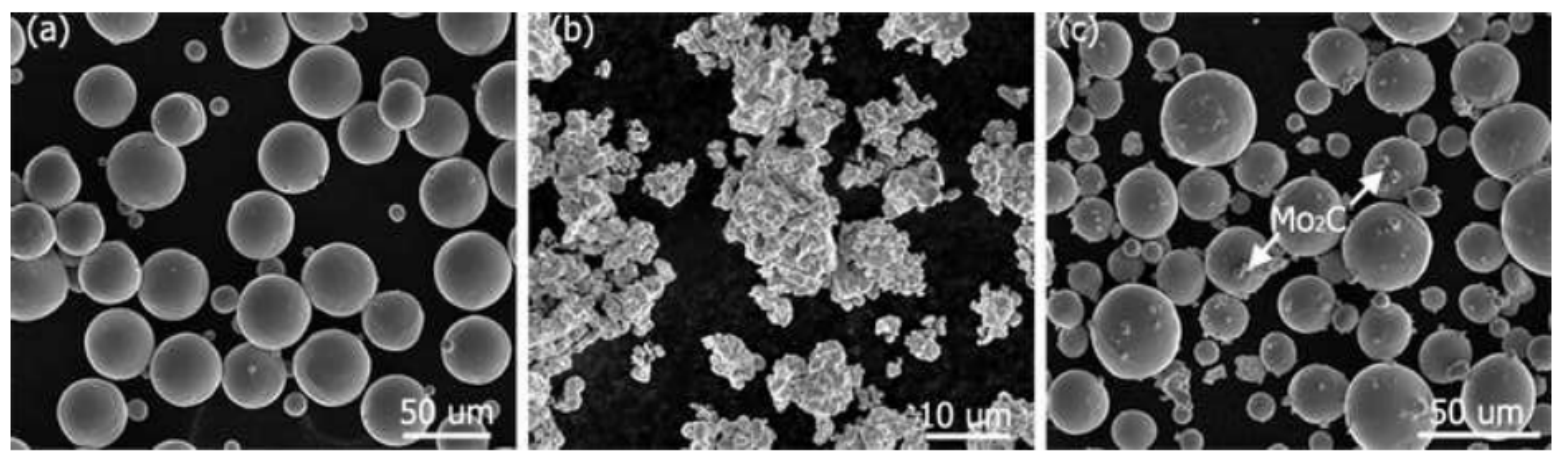

Figure 1 


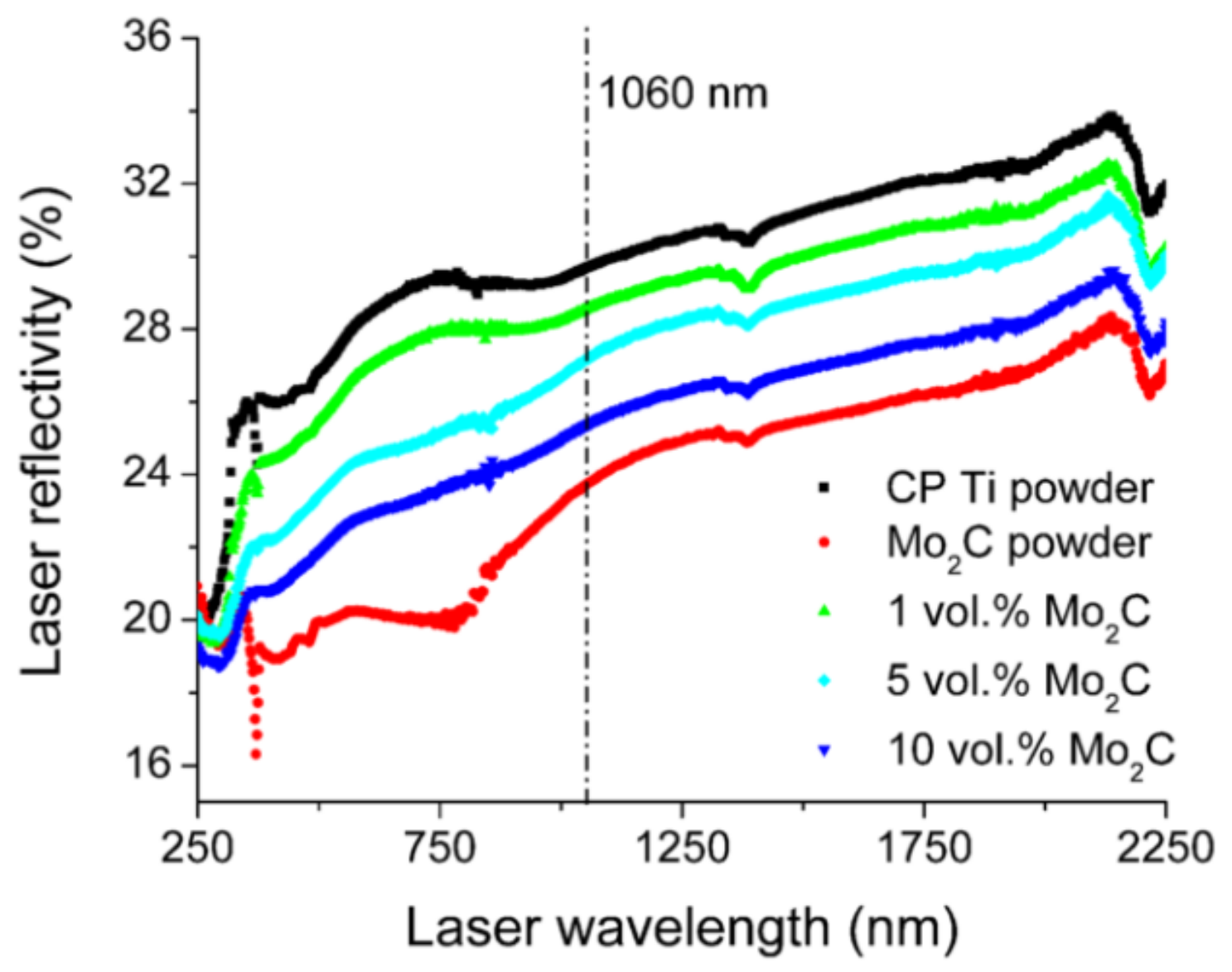

Figure 2 


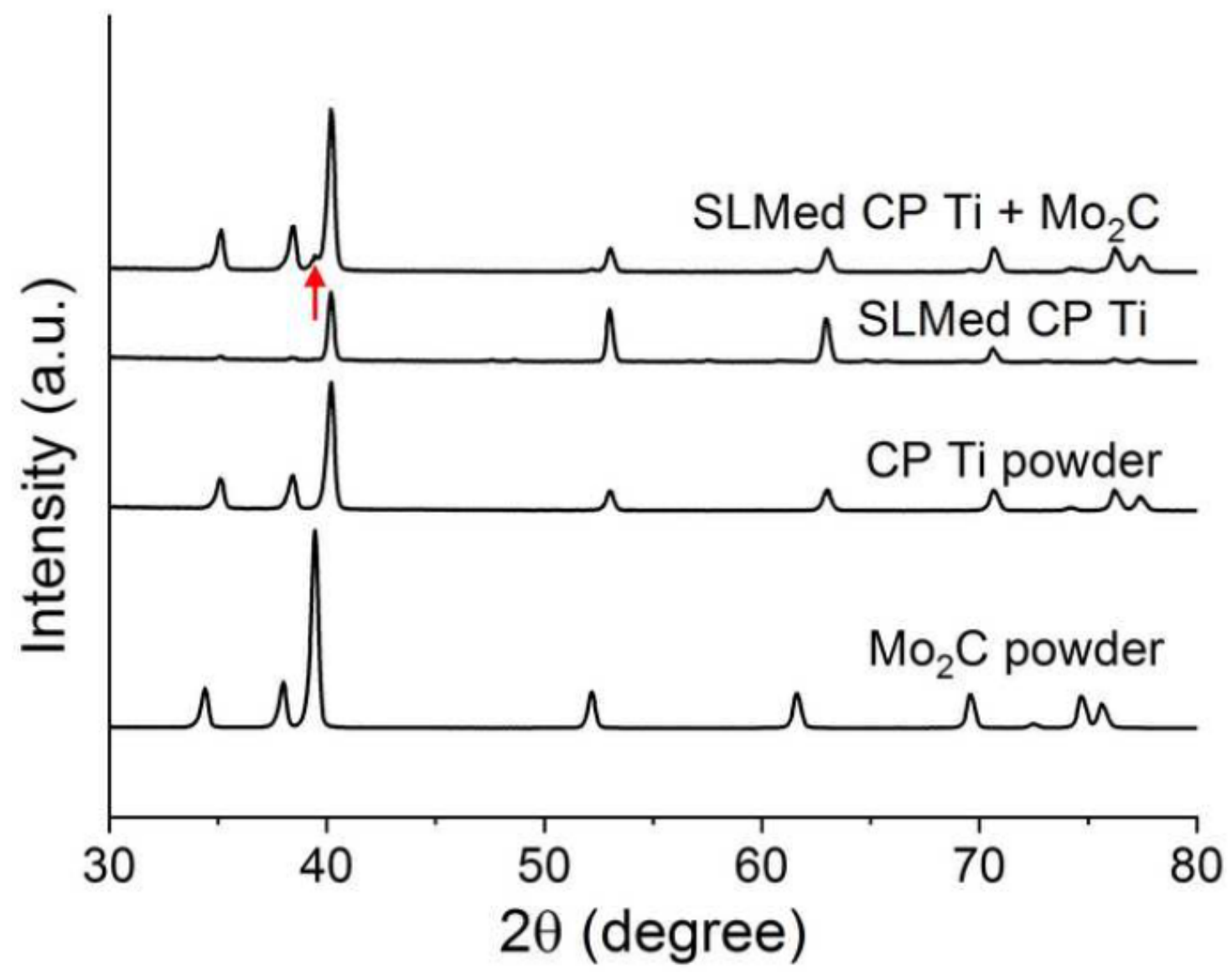

Figure 3 

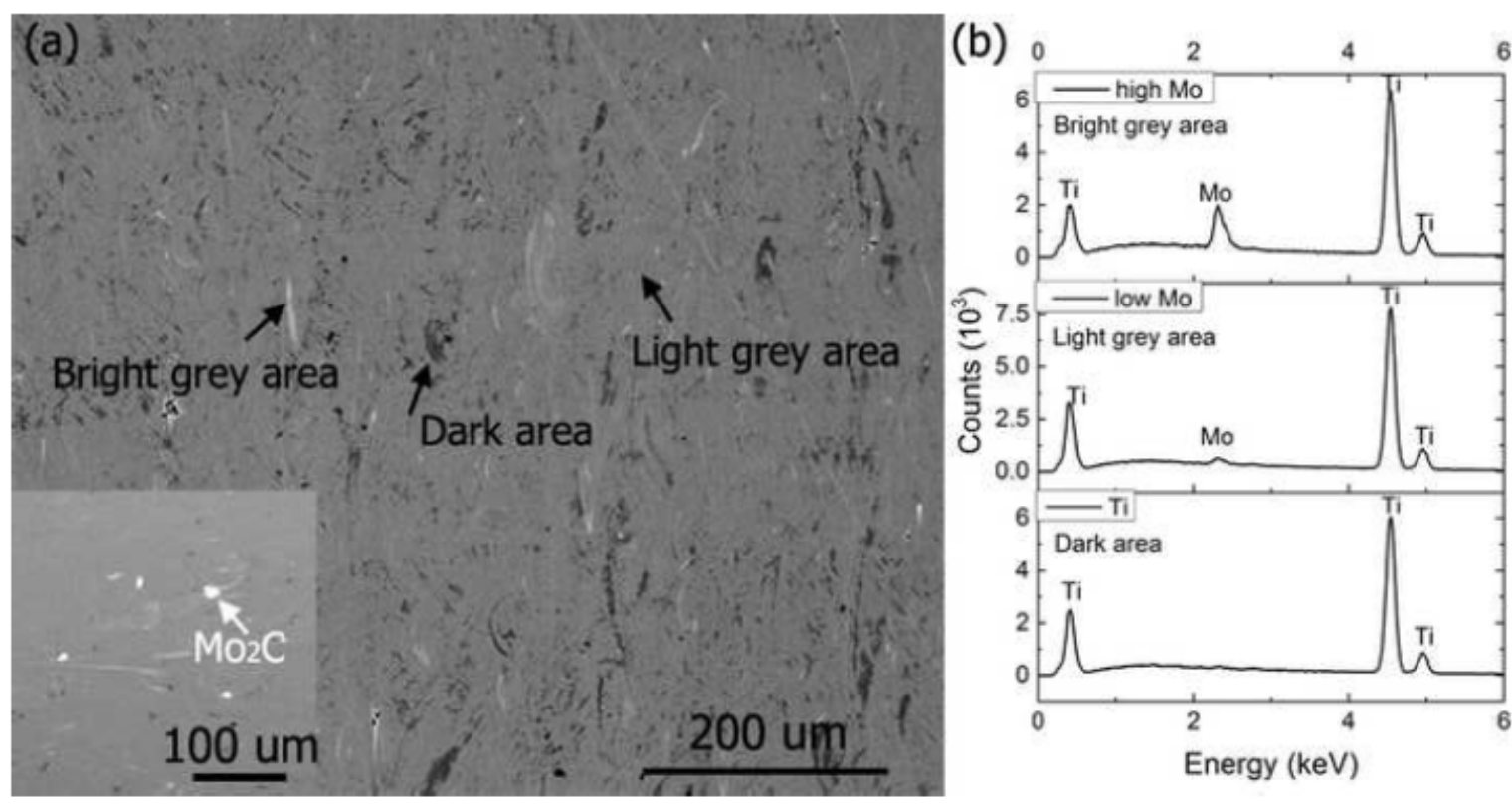

Figure 4 

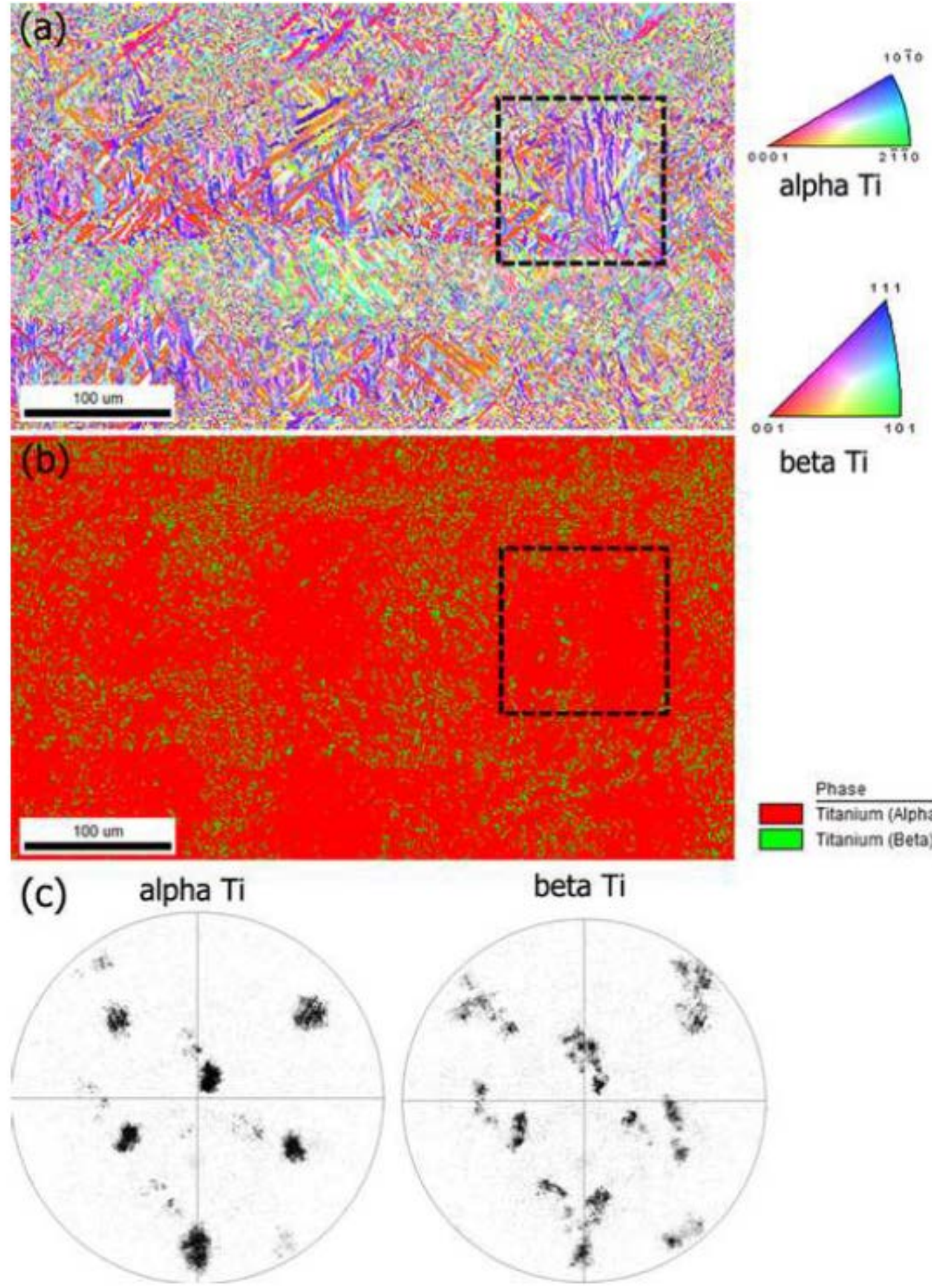

beta $\mathrm{Ti}$

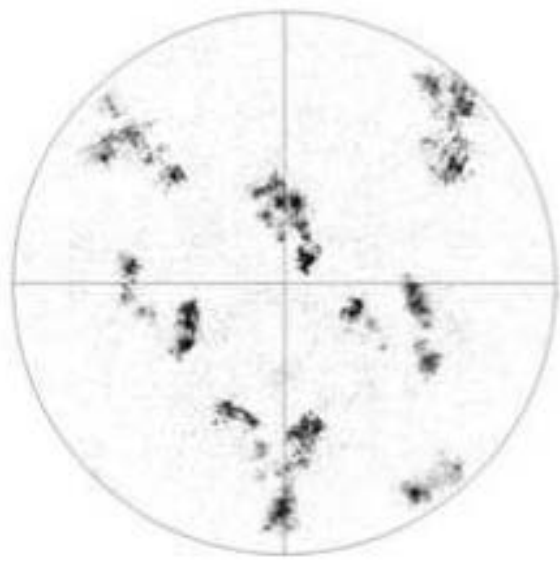

Figure 5 


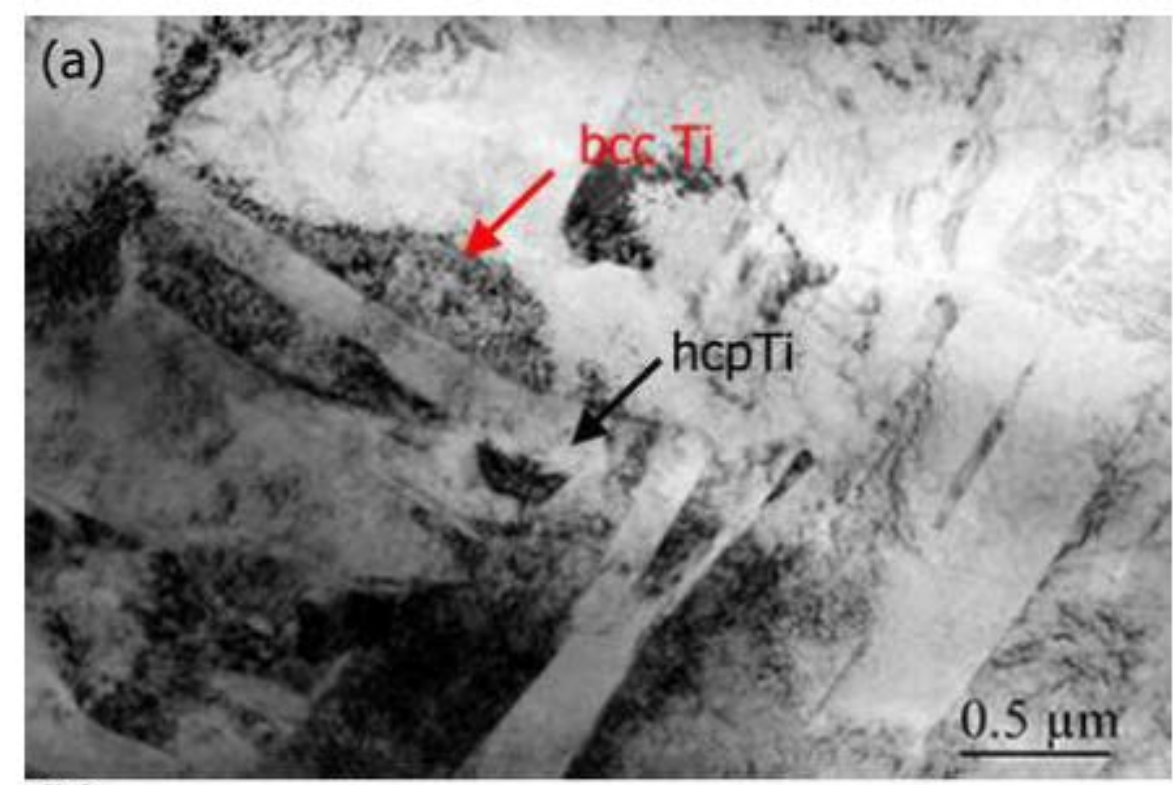

(b)
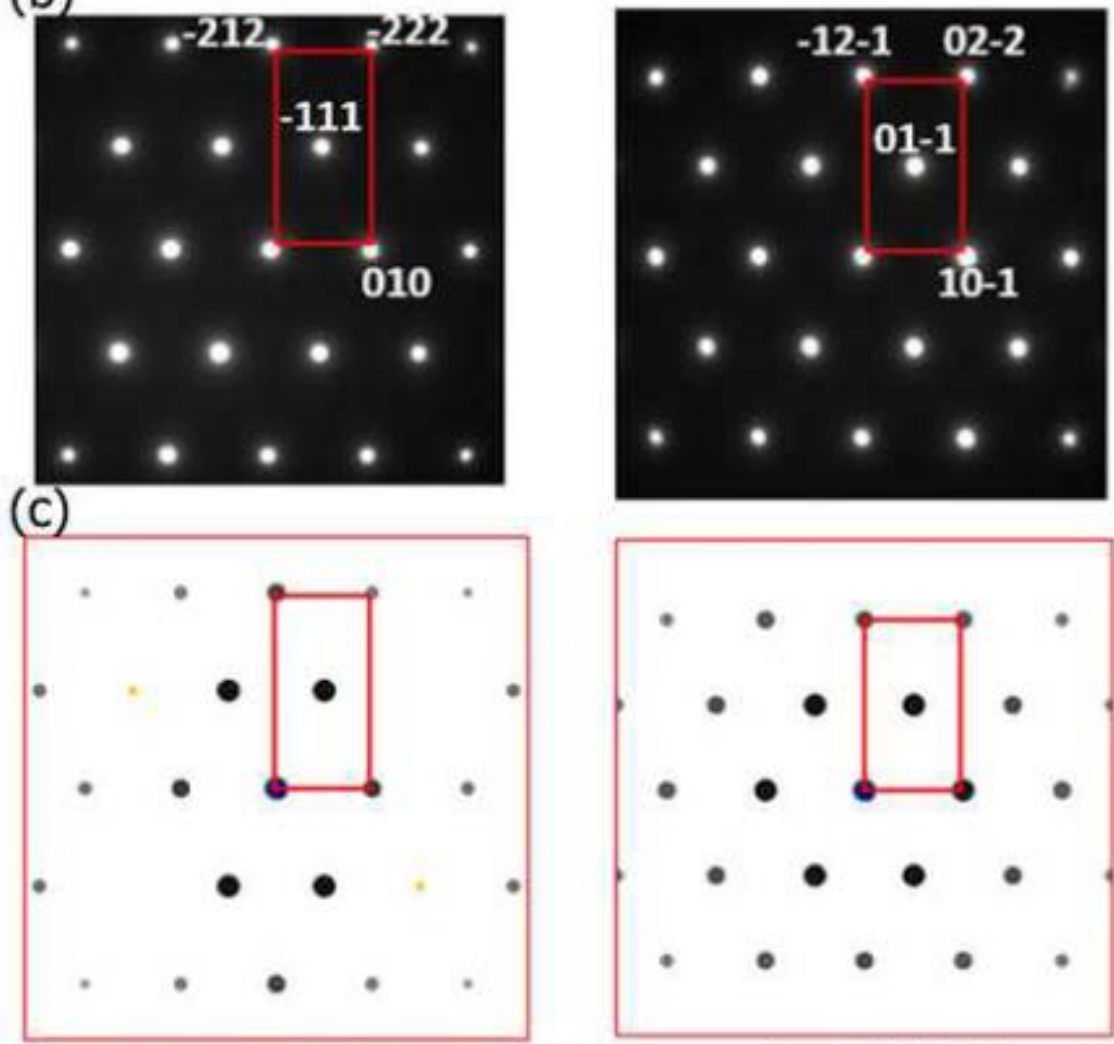

hcp Ti [101]

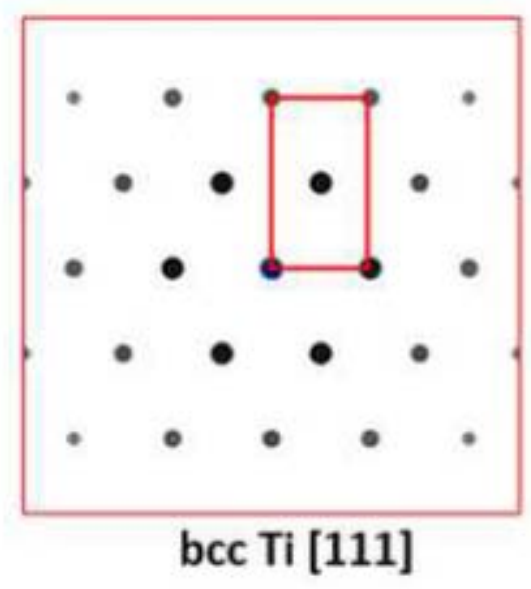

Figure 6 


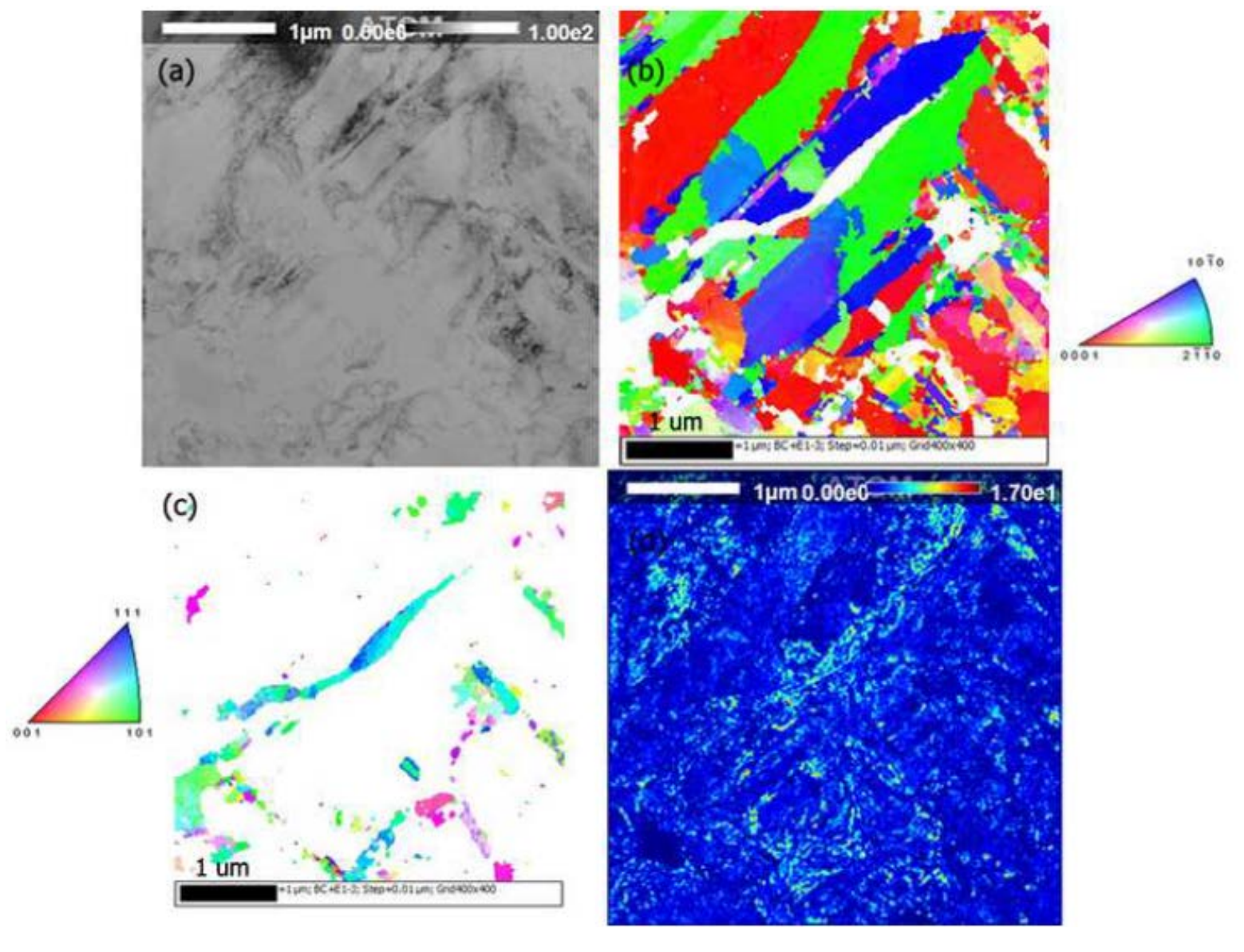

Figure 7 


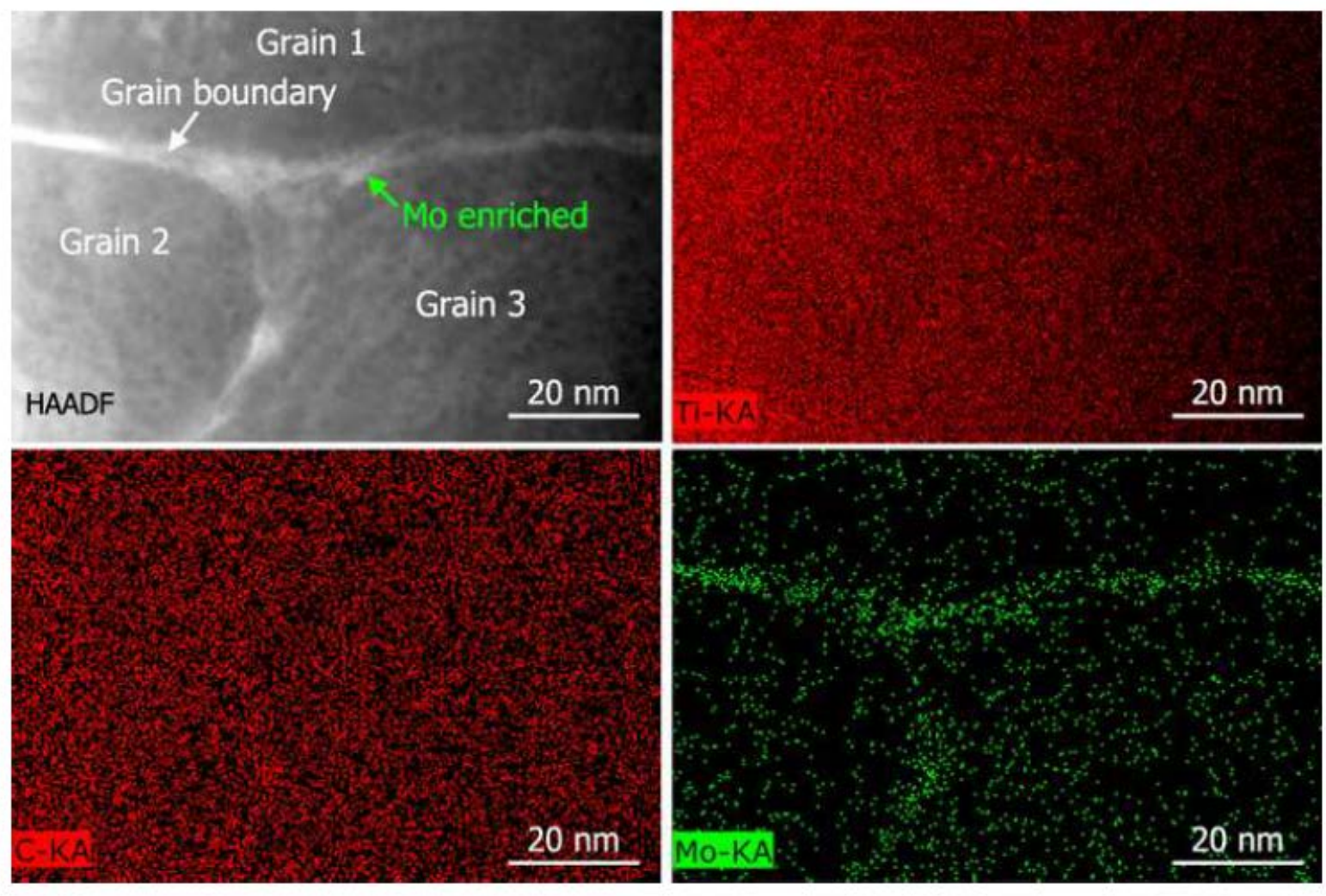

Figure 8 


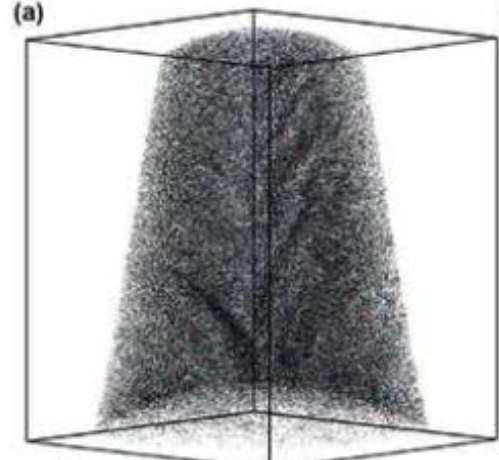

$5 \overline{n m}$ (b)
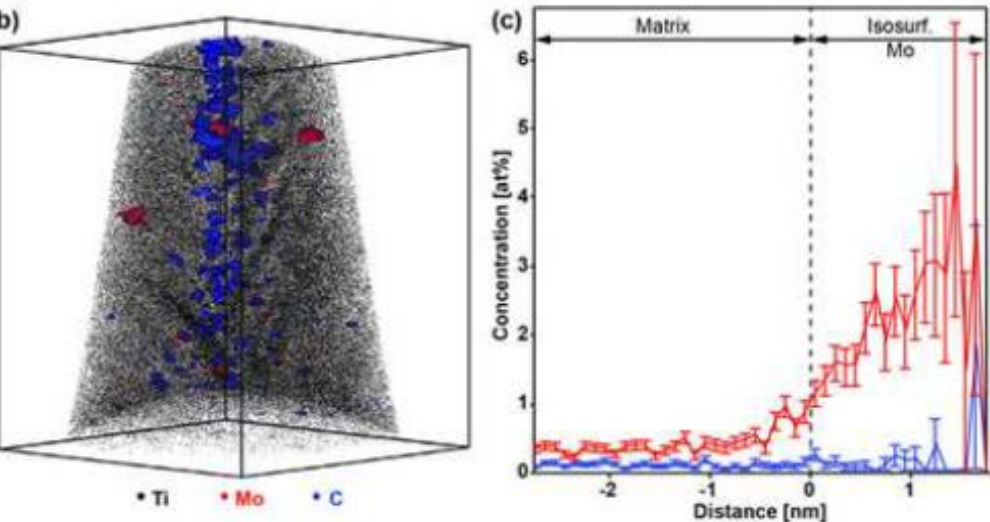

Figure 9 

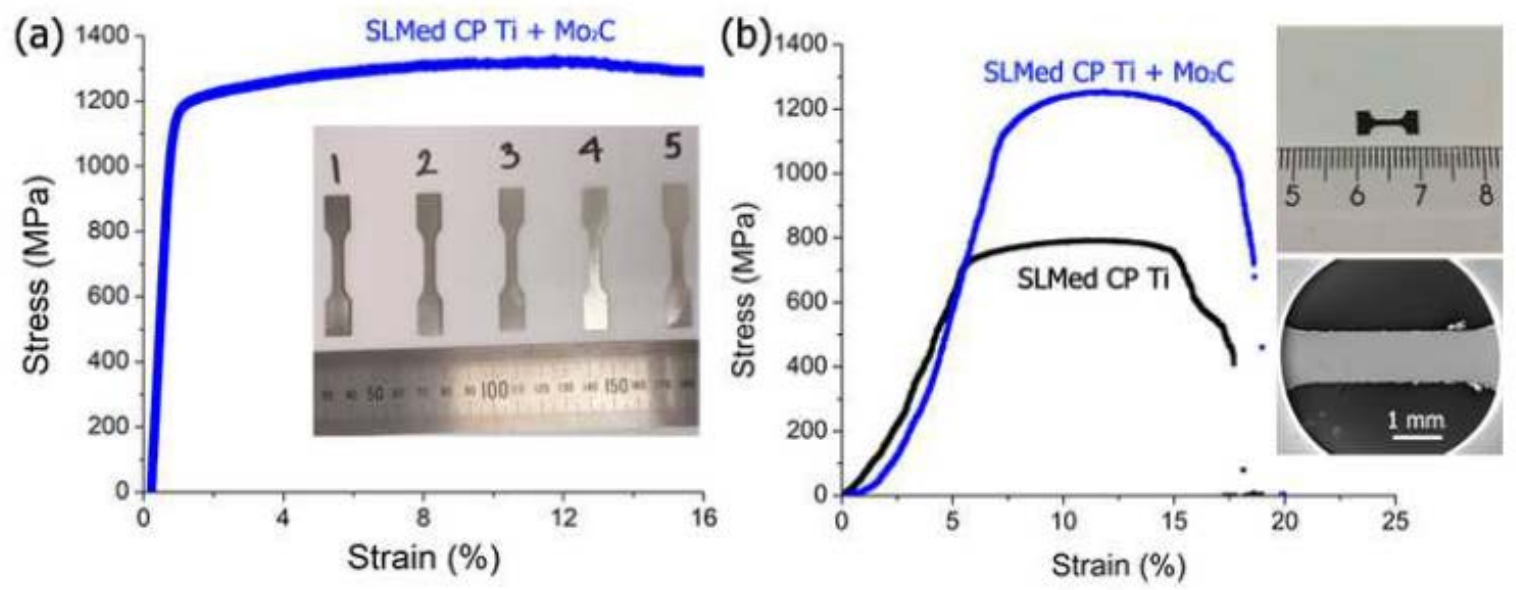

Figure 10 

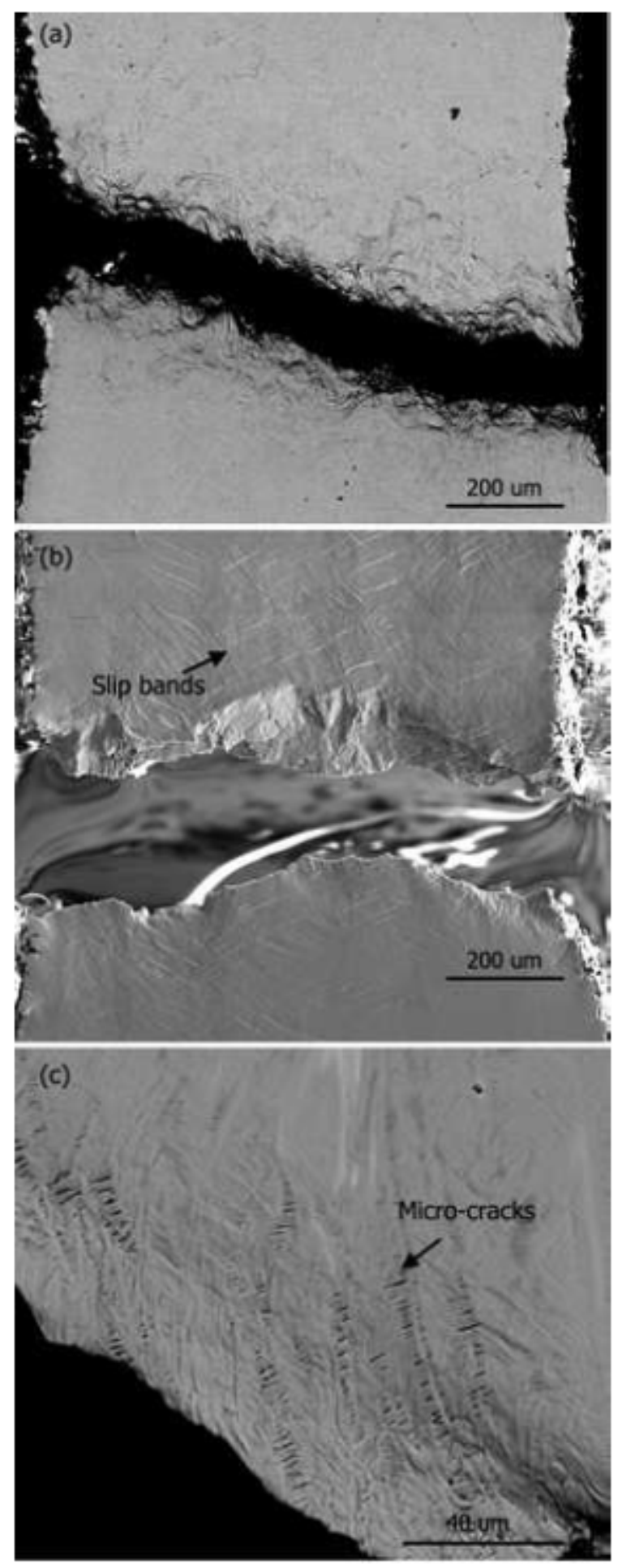

Figure 11 